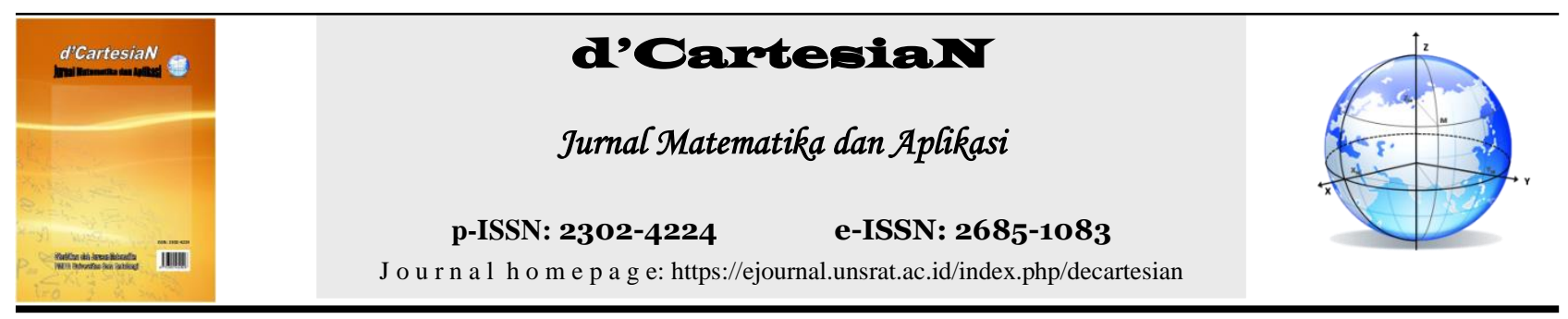

\title{
Penerapan Analisis Faktor Terhadap Kualitas dan Kepuasaan Pelayanan Pasien Rumah Sakit TK-II R.W Mongisidi
}

\author{
Rocky Lintong1, Yohanes A. R. Langi ${ }^{1}$, Charles E. Mongi ${ }^{*}$ \\ ${ }^{1}$ Jurusan Matematika-Fakultas Matematika dan Ilmu Pengetahuan Alam-Universitas Sam Ratulangi Manado, Indonesia \\ *Corressponding author: charlesmongi@unsrat.ac.id
}

\begin{abstract}
A B S T R A K
Rumah sakit merupakan salah satu institusi yang menyediakan berbagai pelayanan bagi berupa dokter, perawat dan tenaga ahli untuk orang-orang yang sakit. Pelayanan merupakan salah satu faktor utama bukan hanya bagi rumah sakit tapi juga untuk berbagai institusi lainnya. Dalam penelitian ini digunakan analisis faktor untuk menentukan kepuasan dan kualitas pelayanan Rumah Sakit TK-II R. W Mongisidi dengan menggunakan aplikasi perhitungan statistik. Tujuan dari penelitian ini adalah untuk mengetahui analisis faktor terhadap kualitas dan pelayanan Rumah Sakit TK-II R. W Mongisidi dan untuk menentukkan penerapan analisis faktor terhadap kualitas dan pelayanan Rumah Sakit TK-II R. W Mongisidi. Dengan hasil penelitian yang diperoleh adalah bahwa pasien rawat inap Rumah Sakit TK-II R. W Mongisidi sudah cukup puas terhadap pelayanan yang diberikan Rumah Sakit dengan tingkat kepuasan yang diperoleh hasil $64.484 \%$.
\end{abstract}

\section{INFO ARTIKEL}

Diterima : 10 Oktober 2019

Diterima setelah revisi : 23 Oktober 2019

Tersedia online : 28 Oktober 2019

\section{Kata Kunci:}

Analisis Faktor,

Rumah Sakit,

Kualitas Pelayanan,

\begin{abstract}
A B S T RA C T
The hospital is one of the institutions that provide various services for doctors, nurses and experts for people who are sick. Service is one of the main factors not only for hospitals but also for various other institutions. In this study, factor analysis is used to determine satisfaction and service quality of TK W II R. W Mongisidi Hospital using statistical calculation applications. The purpose of this study was to determine the factor analysis of the quality and services of the R. W Mongisidi TK-II Hospital and to determine the application of the factor analysis to the quality and service of the TK-II R. W Mongisidi Hospital. With the results of the research obtained is that the patients of the TK-II R. W Mongisidi Hospital were quite satisfied with the services provided by the Hospital with a satisfaction level of $64,484 \%$.
\end{abstract}

\section{Article Informations}

Received : 10 October 2019

Received in revised form : 23 October 2019

Available online : 28 October 2019

Kata Kunci:

Factor Analysis,

Hospital,

Services Quality,

\section{PENDAHULUAN}

Sumber daya manusia salah satu faktor penting untuk lebih meningkatkan suatu kualitas dalam pelayanan adalah proses membantu orang lain dengan cara-cara tertentu dimana sensitivitas dan kemampuan interpersonal dibutuhkan untuk menciptakan kepuasan dan loyalitas yang ditentukan oleh keakraban, kehangatan, penghargaan kedermawaan dan kejujuran yang dilakukan oleh penyedia jasa sebuah budaya yang kuat yang mewarnai sifat hubungan perusahaan dan pelangganya merupakan identitas memenangkan pelanggan pengguna produk. Perubahan lingkungan yang cepat dan berkembang baik di tingkat lokal maupun global mendorong rumah sakit untuk melaksanakan berbagai perubahan. Mengingat perubahan yang cenderung semakin cepat dengan munculnya berbagai kebijakan Pemerintah, teknologi, perekonomian, perilaku konsumen, pertumbuhan pasar, strategi pesaing dan faktor-faktor lain yang mengakibatkan situasi persaingan semakin tajam, maka dibutuhkan strategi yang tepat dalam mengelola pelayanan kesehatan di rumah sakit (Laksono, 2008).
Rumah Sakit adalah suatu organisasi yang melalui tenaga medis profesional yang terorganisir serta sarana kedokteran yang menyelenggarakan pelayanan kedokteran, asuhan keperawatan yang berkesinambungan, diagnosis serta pengobatan penyakit yang diderita oleh pasien.

Penelitian mengenai penerapan tingkat kepuasan Mahasiswa terhadap kualiatas pelayanan Universitas Sam Ratulangi menggunakan Analisis Faktor sebelumnya telah dilakukan oleh Lombone, dkk (2012). Penelitian mengenai analisis faktor ini juga pernah dilakukan oleh Mamahit, dkk (2013). dengan judul tingkat kepuasan dosen dan tenaga kependidikan terhadap Universitas Sam Ratulangi menggunakan Analisis Faktor. Maka akan dilakukan penelitian lebih lanjut dengan menggunakan metode Analisis Faktor sebagai metode utama penelitian.

Berdasarkan hal tersebut maka akan dilakukan analisa terhadap tingkat kepuasan pasien dengan menggunakan metode analisis faktor. Proses penelitian akan menggunakan kuesioner yang akan diberikan kepada pasien-pasien yang ada di Rumah sakit TK-II R.W Mongisidi dengan tingkat kualitas pelayanan yang 
sama untuk dapat mempermudah dalam proses pengolahan data. Manfaat penelitian ini adalah untuk membantu masyarakat dalam memilih rumah sakit yang pelayanannya berkualitas di mana setiap rumah sakit memiliki kualitas pelayanan yang berbeda-beda dan tentunya sebagai masyarakat menginginkan pelayanan yang berkualitas.

Dengan penelitian ini diharapkan bisa membantu rumah sakit untuk mengembangkan dan membantu meninjau kinerjanya dalam melayani guna membuat pasien merasa nyaman dan puas dengan seluruh fasilitas yang ada pada Rumah Sakit. Diharapkan penelitian ini juga dapat membantu dalam proses pemahaman metode analisis faktor dengan menggunakan aplikasi dan memberikan pengetahuan dalam penggunaan analisis faktor untuk proses menentukan mutu pelayanan.

\section{Rumusan Masalah}

Berdasarkan latar belakang maka permasalahan yang akan di selesaikan dalam penelitian ini adalah Analisis Faktor Terhadap Kualitas dan Kepuasan Pelayanan Pasien Rumah Sakit TK-II R.W Mongisidi.

\section{Tujuan}

Tujuan dalam penelitian ini adalah untuk mengetahui penerapan analisis faktor terhadap kualitas dan kepuasan pasien Rumah Sakit TK-II R.W Mongisidi

\section{Batasan Masalah}

Penelitian ini terbatas yang di teliti pasien yang berada di ruangan golongan umum dan yang di mintai keterangan pada pasien dan keluarga pasien yang \pm $2 \times 24$ jam masuk rumah sakit.

\section{Manfaat Penelitian}

Manfaat penelitian ini adalah untuk Membantu Kebijakan Pihak Rumah Sakit dalam Meningkatkan Kualitas dan Kepuasaan pasien dalam Pelayanan Rumah Sakit.

\section{Kualitas Pelayanan}

Kualitas pelayanan (service quality) dapat diketahui dengan cara membandingkan persepsi para konsumen atas pelayanan yang nyata-nyata mereka terima atau peroleh dengan pelayanan yang sesungguhnya mereka harapkan atau inginkan terhadap atribut-atribut pelayanan atau perusahan. Jika jasa di terima atau dirasakan (perceived service) sesuai dengan yang diharapkan, maka kualitas pelayanan dipersepsikan baik dan memuaskan, jika jasa yang diterima melampaui harapan konsumen, maka kualitas pelayanan dipersepsikan sangat baik dan berkualitas. Sebaliknya jika jasa yang diterima lebih rendah dari pada yang diharapkan, maka kualitas pelayanan dipersepsikan buruk.

Pelayanan merupakan perilaku produsen dalam rangka memenuhi kebutuhan dan keinginan konsumen demi tercapainya kepuasan pada konsumen itu sendiri. Menurut kolter kualitas pelayanan dapat diukur dari komponen-komponen sebagai berikut (Ariyanti, 2009)

1. Keandalan (reability): Kemampuan menyelanggarakan jasa dengan dapat diandalkan, akurat, dan konsisten. Komponen ini dianggap sebagai salah satu yang penting bagi konsumen.
2. Cepat tanggap (responsiveness): Kemampuan untuk memberikan pelayanan yang segera. Contoh dari cepat tanggap termasuk di dalamnya menelepon kembali konsumen dengan cepat. Majikan makan siang yang cepat, bagi yang tergesa-gesa, mengirimkan slip transaksi segera.

3. Kepastian (assurance): Pengetahuan dan kesopanan karyawan serta kemampuan untuk menjaga kepercayaan. Karyawan yang berkeahlian yang memperlakukan konsumen dengan serta hormat serta membuat mereka merasa bahwa mereka dapat mempercayai kepastian seperti ditunjukkan perusahan.

4. Empati (empathy): Memperhatikan konsumen secara individual. Perusahan yang pegawainya mengenal konsumennya, memanggil mereka dengan nama, dan belajar memahami tuntutan tertentu konsumen memberikan empati.

5. Berwujud (tangible): Bukti fisik dari jasa. Bagian nyata dari jasa yang meliputi fasilitas fisik, perkakas, dan peralatan yang digunakan untuk menghasilkan jasa.

\section{Analisis Faktor}

Analisis faktor adalah salah satu teknik statistika yang dapat digunakan untuk memberikan deskripsi yang relatif sederhana melalui reduksi jumlah peubah yang disebut faktor. Analisis faktor adalah prosedur untuk mengidentifikasi item atau variabel berdasarkan kemiripannya. Kemiripan tersebut ditunjukkan dengan nilai korelasi yang tinggi. Item-item yang memiliki korelasi yang tinggi akan membentuk satu kerumunan faktor. Prinsip dasar dalam analisis faktor adalah menyederhanakan deskripsi tentang data dengan mengurangi jumlah variabel/dimensi.

\section{Konsep Dasar}

Teknik analisis faktor mulai dikembangkan pada awal abad ke-20 oleh Spearman (Widarjono, 2010) meskipun ada berapa ahli mengatakan bahwa analisis faktor ini telah dikembangkan lebih dulu oleh ahli stastistika yang lain yaitu karl pearson pada tahun 1901 . Analisis faktor terdiri dari dua yaitu analisis faktor eksploratori (exploratory factor analysis $=\mathrm{EFA}$ ) dan analisis faktor konfirmatori (confirmatory factor analysis $=\mathrm{CFA}$ ). Pada penelitian ini menggunakan analisis faktor eksploratori yang digunakan untuk mencari sejumlah indikator untuk membentuk faktor umum (common factor) tanpa ada landasan teori sebelumnya. Analisis faktor merupakan salah satu dari analisis ketergantungan (interpendensi) antar variabel. Analisis faktor yang sering digunakan untuk mengurangi sejumlah besar respon untuk satu set yang lebih kecil dari skor yang tidak berkolerasi (Morrison, 1978) Prinsip dasar analisis faktor adalah mengekstraksi sejumlah faktor bersama (common factors) dari gugusan variabel asal $\mathrm{X}_{1}, \mathrm{X}_{2}, \ldots, \mathrm{Xp}$, sehingga :

- Banyaknya faktor lebih sedikit dibandingkan dengan banyaknya variabel asal $\mathrm{X}$.

Sebagian besar informasi (ragam) variabel asal $\mathrm{X}$, tersimpan dalam sejumlah faktor.

\section{Model Matematika Analisis Faktor}

Misalkan variabel acak X dengan p komponen memiliki rataaan $\mu$ dan peragam (covarian) matriks $\Sigma$. Model faktor dibentuk agar x menjadi linear dan bergantung dengan beberapa peubah acak yang tidak dapat terobservasi, yaitu $F_{1}, F_{2}, F_{3} \ldots \ldots, F_{n}$ (faktor bersama) yang disebut faktor umum, faktor loading 
(loading factors) $\mathrm{l}$ dan $\mathrm{p}$ sumber keragaman $\varepsilon_{1}, \varepsilon_{2}, \varepsilon_{3}, \ldots, \varepsilon_{n}$ yang disebut eror atau galat atau faktorfaktor spesifik (faktor khusus). Sehingga persamaan umum analisis faktor dapat dirumuskan sebagai berikut: $X-\mu=L F+\varepsilon$

$X_{1}-\mu_{1}=\mathrm{l}_{11} F_{1}+\mathrm{l}_{12} F_{2}+\mathrm{l}_{13} F_{3}+\cdots \ldots+\mathrm{l}_{1 n} F_{n}+\varepsilon_{1}$

$X_{2}-\mu_{2}=\mathrm{l}_{21} F_{1}+\mathrm{l}_{22} F_{2}+\mathrm{l}_{23} F_{3}+\cdots \ldots+\mathrm{l}_{2 n} F_{n}+\varepsilon_{2} X_{p}-$

$\mu_{p}=\mathrm{l}_{p 1} F_{1}+\mathrm{l}_{p 2} F_{2}+\mathrm{l}_{p 3} F_{3}+\cdots \ldots+\mathrm{l}_{p n} F_{n}+\varepsilon_{p}$

Misalkan $X=\left(X_{1}, \ldots, X_{p}\right)$ dengan $n$ peubah acak yang tidak dapat diobservasi, diasumsikan $\mathrm{n}<\mathrm{p}$, maka secara matriks dapat dirumuskan:

$\left(\begin{array}{c}X_{1} \\ X_{2} \\ \vdots \\ X_{p}\end{array}\right)-\left(\begin{array}{c}\mu_{1} \\ \mu_{2} \\ \vdots \\ \mu_{p}\end{array}\right)=\left(\begin{array}{cccc}X_{1} & l_{11} & \mathrm{l}_{1 n} \\ X_{2} & \mathrm{l}_{21} & \ldots & \mathrm{l}_{2 n} \\ \vdots & \vdots & \vdots & \vdots \\ X_{p} & l_{p 1} & \mathrm{l}_{p n}\end{array}\right)\left(\begin{array}{c}F_{1} \\ F_{2} \\ \vdots \\ F_{p}\end{array}\right)+\left(\begin{array}{c}\varepsilon_{1} \\ \varepsilon_{2} \\ \vdots \\ \varepsilon_{p}\end{array}\right)$

Model analisis faktor mensyaratkan bahwa hubungan antar variabel terobservasi harus linier dan nilai koefisien korelasi tidak boleh nol, artinya harus benarbenar ada hubungan yang kuat $(\mathrm{r}=0,5$ atau $-0,5)$.

\section{Langkah-Langkah Melakukan Analisis Faktor} Langkah pertama dalam analisis faktor adalah merumuskan masalah faktor analisis dan mengidentifikasi atau mengenali variabel-variabel asli yang akan dianalisis faktor. Kemudian suatu matriks korelasi dari variabel-variabel ini dibentuk dan metode analisis faktor dipilih. Peneliti menentukan banyaknya faktor yang akan disaringkan (extracted) dari variabel yang banyak tersebut dan metode rotasi yang akan digunakan. Langkah berikutnya harus menginterpretasikan faktor hasil rotasi (Supranto, 2004).

\section{Membentuk Matriks Korelasi}

Proses analisis didasarkan pada suatu matriks kolerasi agar variabel yang berguna bisa diperoleh dari penelitian matriks ini. Agar analisis faktor bisa tepat dipergunakan variabel-variabel yang akan dianalisis harus berkolerasi. Penelitian mengharapkan selain variabel asli berkolerasi dengan sesama variabel lainnya. Juga berkolerasi dengan faktor sebagai variabel baru yang disaring dari variabel-variabel asli. Banyaknya faktor lebih sedikit dari pada banyaknya variabel (Supranto, 2004).

Statistik formal tersedia untuk menguji ketetapan model faktor, bartlett's test of sphericyty bisa digunakan untuk menguji hipotesis bahwa variabel tak berkorelasi didalam populasi. Dengan perkataan lain, matriks korelasi populasi merupakan matriks identity, dimana pada diadonal pokok, angkanya 1, diluar diagonal pokok angkanya 0 . Uji statistik untuk sphericyty didasarkan pada suatu transformasi khi kuadrat dari determinasi matriks korelasi.

Nilai yang besar untuk uji statistik, berarti hipotesis o harus ditolak. Kalau hipotesis o diterima, ketetapan analisis faktor harus dipertanyakan. Statistik lainnya yang berguna ialah KMO (Kaiser-Mayer-Olkin) mengukur kecukupan sampling (sampling adequacy). Indeks ini membandingkan besarnya koefisien korelasi terobservasi dengan besarnya koefisien korelasi parsial. Nilai KMO yang kecil menunjukkan bahwa korelasi antar-pasangan variabel tidak bisa diterangkan oleh variabel lainnya dan analisis faktor mungkin tidak tepat. Adapun formula untuk menghitung KMO sebagai berikut (Widarjono, 2010) :

dengan :

$$
\mathrm{KMO}=\frac{\Sigma \Sigma_{i=j} r_{i j}^{2}}{\Sigma \Sigma r_{i j}^{2}+\Sigma \Sigma a_{i j}^{2}}
$$

$r_{i j}=$ koefesien korelasi

$a_{i j}=$ koefesien korelasi parsial

Selain memasukan semua indikator didalam perhitungan korelasi, KMO juga menghitung koefesien korelasi di dalam analisis faktor untuk indikator tertentu (measure of sampling adequacy). Adapun formulanya sebagai berikut :

$$
\mathrm{MSA}=\frac{\Sigma r_{i j}^{2}}{\Sigma r_{i j}^{2}+\Sigma a_{i j}^{2}}
$$

dengan :

$r_{i j}=$ koefesien korelasi

$a_{i j}=$ koefisen korelasi parsial

Jika semakin tinggi nilai koefesien korelasi MSA sangat tepat indikator dimasukan secara individual di dalam analisis Faktor.

\section{METODOLOGI PENELITIAN}

\section{Waktu dan Tempat Penelitian}

Analisis penelitian dilaksanakan selama kurang lebih 2 bulan. Dimulai dari Mei 2019 sampai Juni 2019. Tempat pelaksanan penelitian di Rumah Sakit TK-II R.W Mongisidi dan untuk analisis data di lakukan di Laboratorium Statistika Jurusan Metematika, Fakultas Matematika dan Ilmu Pengetahuan Alam. Universitas Sam Ratulangi Manado

\section{Sumber Data}

Penelitian ini menggunakan data primer melalui kuesioner yang berisi indikator-indikator pelayanan yang diperoleh pasien dan keluarga pasien selama berada dalam ruangan rawat inap RS sampel yang di bagikan langsung pada pasien dan keluarga pasien di masing-masing ruangan.

Populasi yang dijadikan objek penelitian adalah pasien dan keluarga pasien yang berjumlah 938 pasien. Jumlah sampel ditentukan dari banyaknya populasi pasien RS menggunakan metode Slovin yaitu :

$$
\mathrm{n}=\frac{N}{1+N \cdot e^{2}}
$$

dengan :

$\mathrm{n}=$ jumlah sampel

$\mathrm{N}=$ jumlah populasi

$\mathrm{e}=$ persen kelonggaran ketidaktelitian $(0,1)$

\section{Metode Analisis}

Langkah-Langkah yang dilakukan dalam penelitian ini adalah:

1. Input data

2. Pengolahan data menggunakan Aplikasi SPSS

3. Langkah-langkah mengunakan Analisis Faktor adalah sebagai berikut (Widarjano, 2010)

1. Membentuk matriks korelasi yang terdiri dari variabel (n) dan jumlah responden $(p)$ dengan ukuran $(n \times p)$

2. Menghitung matriks korelasi untuk mengetahui syarat kecukupan data dengan menggunakan barlett's test of sphericity dan Kaiser-Mayer Olkin (KMO), dimana nilai $\mathrm{KMO} \geq 0,5$

3. Menentukan variabel-variabel mana yang layak untuk analisis faktor dengan melihat nilai $\mathrm{MSA} \geq 0,5$.

4. Metode Communalities

5. Metode Variance Explained

6. Proses rotasi faktor

7. Interpretasi faktor 


\section{HASIL DAN PEMBAHASAN}

\section{Input Data}

Data penelititan di dapat dengan menggunakan kuesioner yang di jalankan di Rumah Sakit TK-II R.W Mongisidi. Dengan menggunkan metode slovin maka di dapatkan:

$$
\mathrm{n}=\frac{938}{1+(938)\left(0,1^{2}\right)}=90.36=91
$$

91 data yang di dapatkan lalu dimasukan ke dalam Aplikasi pengolahahn datayang kemudian diolah dengan menggunakan aplikasi statistika.

\section{Analisis Faktor}

Analisis faktor dimaksudkan untuk menemukan variabel baru yang disebut faktor yang jumlahnya lebih sedikit dibandingkan dengan variabel asli yang tidak berkorelasi satu sama lainnya. Untuk mengetahui faktor-faktor dan variabel pembentuk faktor yang menentukan kepuasan pasien, digunakan analisis faktor. Analisis faktor yang digunakan dalam penelitian ini adalah principal components analysis. Variabelvariabel yang dianalisis dalam penelitian ini adalah bukti fisik yang terdiri dari 9 item pernyataan, handal dengan 6 item pertanyaan, tanggap dengan 5 item pertanyaan, perhatian dengan 4 pernyataan, dan jaminan dengan 4 pertanyaan yang dimuat dalam kuisioner, dengan sampel sebesar 91 responden. Jumlah sampel dan banyaknya item pertanyaan ini kemudian dibuat dalam bentuk matriks korelasi dengan ukuran 28 x 91 Terlihat pada Lampiran 1.

\section{Uji KMO Dan Bartlett}

Variabel-variabel yang telah ditentukan selanjutnya diuji untuk mengukur kecukupan sampel dengan cara membandingkan besarnya koefisien korelasi yang diamati dengan koefisien korelasi parsialnya. Dalam hal ini digunakan uji KMO (KaiserMayer-Olkin). Uji selanjutnya adalah uji bartlett's test of sphericity yang tujuannya adalah unutk mengetahui apakah ada korelasi yang signifikan antar variabel.

Dari tabel KMO dan bartlett's test ternyata hasilnya menunjukkan bahwa nilai Kaiser-Meyer-Olkin Measure of Sampling Adequancy adalah sebesar 0.620 yang artinya ada korelasi yang cukup signifikan antar indikator mengingat angka ini sudah berada diantar nilai 0,5. Begitu juga dengan bartlett's test sphericity yang mempunyai nilai 303.480 dengan nilai signifikanya sebesar 0,001 yang artinya bahwa faktor pembentuk variabel ini sudah baik untuk dianalisis lebih lanjut.

\section{KMO and Bartlett's Test}

\begin{tabular}{|l|r|}
\hline \multicolumn{2}{|l|}{ Kaiser-Meyer-Olkin } \\
Measure of Sampling
\end{tabular}

\section{Anti-Image Matrices}

Setelah terpenuhi syarat pada uji KMO dan bartlett's test sphericity, langkah selanjutnya adalah melihat indikator-indikator mana yang layak unutk analisis faktor. Prosedurnya jika nilai MSA $\geq 0,5$ maka indikator atau variabel tersebut layak untuk digunakan untuk analisis faktor. Anti Image Matrices menyediakan informasi ini untuk menyeleksi variabel mana yang layak. Informasi ini tersedia di dalam Anti Image
Correlation yang diberi tanda "a" yang membentuk garis diagonal. Terlihat bahwa nilai MSA untuk semua variabel diatas 0,5 sehingga analisis dapat dilanjutkan Terlihat pada Lampiran 3 .

\section{Communalities}

Setelah menguji variabel-variabel maka selanjutnya melakukan proses factoring atau menurunkan satu atau lebih faktor dari variabel-variabel yang telah lulus uji variabel sebelumnya. Communalities merupakan nilai yang menunjukkan kontribusi variabel tersebut terhadap faktor yang terbentuk. Communalities pada dasarnya adalah jumlah varian (dalam presentase). Angka initial disini unutk mengetahui varian suatu faktor dengan masing-masing faktor mempunyai angka 1 yang menunjukan jumlah varian dari faktor mula-mula yang bisa dijelaskan oleh faktor yang terbentuk. Bisa kita lihat pada variabel 1 angkanya adalah 0,659 . Ini berarti sekitar 65,9\% varian dari variabel 1 bisa dijelaskan oleh faktor yang terbentuk. Demikian juga untuk variabel selanjutnya, dengan ketentuan bahwa semakin besar Communalities sebuah variabel, maka semakin erat hubungannya dengan faktor yang terbentuk.

\begin{tabular}{|l|r|r|}
\hline & Initial & Extraction \\
\hline V1 & 1.000 & .659 \\
V2 & 1.000 & .616 \\
V3 & 1.000 & .593 \\
V4 & 1.000 & .703 \\
V5 & 1.000 & .675 \\
V6 & 1.000 & .567 \\
V7 & 1.000 & .735 \\
V8 & 1.000 & .589 \\
V9 & 1.000 & .652 \\
V10 & 1.000 & .599 \\
V11 & 1.000 & .633 \\
V13 & 1.000 & .641 \\
V14 & 1.000 & .554 \\
V16 & 1.000 & .729 \\
V17 & 1.000 & .625 \\
V18 & 1.000 & .638 \\
V19 & 1.000 & .595 \\
V21 & 1.000 & .656 \\
V23 & 1.000 & .785 \\
V25 & 1.000 & .579 \\
V26 & 1.000 & .625 \\
V27 & 1.000 & .739 \\
\hline
\end{tabular}

Total Variance Explained

Pada tampilan total variance explained menjelaskan tentang besarnya varian yang dapat dijelaskan oleh faktor yang terbentuk. Bila total initial eigen values $\geq 1$, maka faktor tersebut dapat menjelaskan variabel dengan baik sehingga perlu diikutsertakan dalam pembentukan variabel (Widarjono, 2010). Sebaliknya jika initial eigenvalues < 1 , faktor tersebut tidak dapat menjelaskan variabel dengan baik sehingga tidak diikutsertakan dalam pembentukan variabel. Berdasarkan nilai initial eigenvalues maka faktor yang terbentuk sebanyak 9 faktor, dengan masing-masing mempunyai nilai eigenvalues 2.767, 2.381, 1.757, 1.550, 1.337, 1.186, 1.101, 1.092, 1.016. Sesuai jumlah faktor yang terbentuk, selanjutnya dapat dijelaskan oleh masing-masing faktor maupun oleh keseluruhan faktor.

Jika 22 faktor diekstrak menjadi 1 faktor, maka: $2,767 / 22 \times 100 \%=12,577 \%$, artinya jika 22 variabel tersebut dijadikan 1 faktor maka faktor 
tersebut mampu menjelaskan varian variabel sebesar $12,577 \%$

Jika 22 faktor diekstrak menjadi 2 faktor, maka: $2,381 / 22 \times 100 \%=10,821 \%$, artinya jika 22 variabel tersebut dijadikan 1 faktor maka faktor tersebut mampu menjelaskan varian variabel sebesar $10,821 \%$.

- Jika 22 faktor diekstrak menjadi 3 faktor, maka : 1,757/22 x 100\% = 7,987\%, artinya jika 22 variabel tersebut dijadikan 1 faktor maka faktor tersebut mampu menjelaskan varian variabel sebesar 7,987\%

- Jika 22 faktor diekstrak menjadi 4 faktor, maka $: 1,550 / 22 \times 100 \%=7,046 \%$, artinya jika 22 variabel tersebut dijadikan 1 faktor maka faktor tersebut mampu menjelaskan varian variabel sebesar 7,046\%

Jika 22 faktor diekstrak menjadi 5 faktor, maka $: 1,337 / 22 \times 100 \%=6,078 \%$, artinya jika 22 variabel tersebut dijadikan 1 faktor maka faktor tersebut mampu menjelaskan varian variabel sebesar 6,078\%

Jika 22 faktor diekstrak menjadi 6 faktor, maka $: 1,186 / 22 \times 100 \%=5,393 \%$, artinya jika 22 variabel tersebut dijadikan 1 faktor maka faktor tersebut mampu menjelaskan varian variabel sebesar 5,393\%

- Jika 22 faktor diekstrak menjadi 7 faktor, maka $: 1,101 / 22 \times 100 \%=5,003 \%$, artinya jika 22 variabel tersebut dijadikan 1 faktor maka faktor tersebut mampu menjelaskan varian variabel sebesar 5,003\%

Jika 22 faktor diekstrak menjadi 8 faktor, maka $: 1,092 / 22 \times 100 \%=4,963 \%$, artinya jika 22 variabel tersebut dijadikan 1 faktor maka faktor tersebut mampu menjelaskan varian variabel sebesar 4,963\%

- Jika 22 faktor diekstrak menjadi 9 faktor, maka $: 1,016 / 22 \times 100 \%=4,616 \%$, artinya jika 22 variabel tersebut dijadikan 1 faktor maka faktor tersebut mampu menjelaskan varian variabel sebesar $4,616 \%$

Karena kita mempunyai 9 faktor maka 9 faktor tersebut mampu menjelaskan $64,484 \%(12,577 \%+$ $10,821 \%+7,987 \%+7,046 \%+6,078 \%+5,393 \%+$ $5,003 \%+4,963 \%+4,616 \%)$ total varian dari 22 variabel yang ada. Angka ini cukup besar karena mampu menjelaskan lebih dari 50\% varian dari 22 variabel yang ada (Widarjono, A. 2010). Untuk lebih memperjelas bagaimana pembentukan ke Sembilan faktor tersebut dapat digunakan juga scree plot, menurut

(Supranto, 2004) mengatakan bahwa scree plot merupakan suatu plot dari eigenvalues sebagai fungsi banyaknya faktor, dimana sumbu horizontal menyatakan banyaknya faktor dan sumbu vertikal menyatakan eigenvalues, gambar dibawah menunjukan bahwa titik pada tempat dimana the scree mulai terjadi, menunjukkan banyaknya faktor yang benar. Tepatnya pada saat scree mulai merata Terlihat pada gambar 1 .

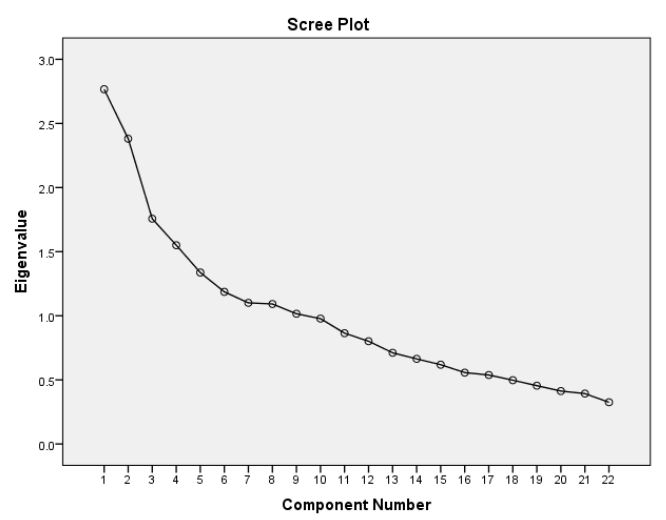

Gambar 1. Scree Plot

\section{Rotasi Faktor}

Pada penelitian ini menggunakan metode rotasi varimax. Tujuan rotasi faktor berusaha meminimumkan banyaknya variabel dengan muatan tinggi (high loading) pada satu faktor, dengan demikian memudahkan pembuatan interpretasi mengenai faktor karena variabel yang masuk dalam faktor tertentu dapat terlihat dengan jelas.

Dapat dilihat pada Lampiran 6, mana yang berkorelasi kuat dengan faktor 1, faktor 2, faktor 3, faktor 4, faktor 5, faktor 6, faktor 7, faktor 8 dan faktor 9 . Faktor-faktor inilah yang menentukan kepuasan mahasiswa terhadap pelayanan Rumah Sakit TK-II R.W Mongisidi.

1. Faktor 1 terdiri dari variabel 1, 2, 3, 4,

2. Faktor 2 terdiri dari variabel $7,9,10,14$

3. Faktor 3 terdiri dari variabel 18, 21

4. Faktor 4 terdiri dari variabel 16, 23

5. Faktor 5 terdiri dari varibel 8,19

6. Faktor 6 terdiri dari variabel 5,25

7. Faktor 7 terdiri dari variabel 17,27

8. Faktor 8 terdiri dari variabel 13,26

9. Faktor 9 terdiri dari variabel 11

\section{Interpretasi Faktor}

Dengan melihat total variance explained, grafik scree plot, dan rotated component matrix, selanjutnya interpretasikan hasil analisis faktor. Diperoleh 9 faktor yang dapat mewakili ke-28 variabel yang dianalisis, yaitu Terlihat Pada Lampiran 6:

a. Faktor pertama adalah memberikan bobot kontribusi sebesar 12,577\%. Berdasarkan hasil rotasi urutan variabel yang dominan dalam menjelaskan faktor pertama $\left(\mathrm{F}_{1}\right)$ diperlihatkan pada tabel 1 :

Tabel 1. Rotasi Komponen Matrix satu

\begin{tabular}{|c|l|l|}
\hline Urutan & \multicolumn{1}{|c|}{ Variabel } & $\begin{array}{l}\text { Nilai } \\
\text { Loading }\end{array}$ \\
\hline 1 & $\begin{array}{l}\text { Penampilan perawat } \\
\text { bersih dan rapi (X4) }\end{array}$ & 0,789 \\
\hline 2 & $\begin{array}{l}\text { Penampilan dokter } \\
\text { bersih dan rapi (X3) }\end{array}$ & 0,745 \\
\hline 3 & $\begin{array}{l}\text { Ruang rawat inap } \\
\text { tertata dengan rapi } \\
\text { dan bersih (X1) }\end{array}$ & 0,625 \\
\hline 4 & $\begin{array}{l}\text { Ruang rawat inap } \\
\text { aman dan nyaman } \\
\text { (X2) }\end{array}$ & 0,513 \\
\hline
\end{tabular}


b. Faktor kedua memberikan bobot kontribusi sebesar 10,821\%. Berdasarkan hasil rotasi urutan variabel yang dominan dalam menjelaskan faktor kedua $\left(\mathrm{F}_{2}\right)$ diperlihatkan pada tabel 2:

Tabel 2. Rotasi Komponen Matrix dua

\begin{tabular}{|c|l|l|}
\hline Urutan & \multicolumn{1}{|c|}{ Variabel } & $\begin{array}{l}\text { NilaI } \\
\text { Loading }\end{array}$ \\
\hline 1 & Kebersihan toilet (X9) & 0,783 \\
\hline 2 & $\begin{array}{l}\text { Kecepatan prosedur } \\
\text { pelayanan(X10) }\end{array}$ & 0,607 \\
\hline 3 & $\begin{array}{l}\text { Perawat selalu } \\
\text { memberikan obat } \\
\text { sesuai dengan } \\
\text { prosedur } \\
\text { diberikan dokter (X14) }\end{array}$ & 0,473 \\
\hline 4 & $\begin{array}{l}\text { Memiliki alat medis } \\
\text { lengkap (X7) }\end{array}$ & 0,336 \\
\hline
\end{tabular}

c. Faktor ketiga memberikan bobot kontribusi sebesar $7,987 \%$. Berdasarkan hasil rotasi urutan variabel yang dominan dalam menjelaskan faktor ketiga $\left(\mathrm{F}_{3}\right)$ diperlihatkan pada tabel 3 :

Tabel 3. Rotasi Komponen Matrix tiga

\begin{tabular}{|c|l|l|}
\hline Urutan & \multicolumn{1}{|c|}{ Variabel } & $\begin{array}{l}\text { Nilai } \\
\text { Loading }\end{array}$ \\
\hline 1 & $\begin{array}{l}\text { Dokter membantu } \\
\text { menghilangkan rasa } \\
\text { cemas pada pasien } \\
\text { X21) }\end{array}$ & 0,711 \\
\hline 2 & $\begin{array}{l}\text { Dokter memberikan } \\
\text { penjelasan mengenai } \\
\text { penyakit (X18) }\end{array}$ & 0,642 \\
\hline
\end{tabular}

d. Faktor keempat memberikan bobot kontribusi sebesar 7,046\%. Berdasarkan hasil rotasi urutan variabel yang dominan dalam menjelaskan faktor keempat $\left(\mathrm{F}_{4}\right)$ diperlihatkan pada tabel 4 :

Tabel 4. Rotasi Komponen Matrix empat

\begin{tabular}{|c|l|l|}
\hline Urutan & \multicolumn{1}{|c|}{ Variabel } & $\begin{array}{l}\text { Nilai } \\
\text { Loading }\end{array}$ \\
\hline 1 & $\begin{array}{l}\text { Waktu konsultasi } \\
\text { pasien dan keluarga } \\
\text { terpenuhi (X23) }\end{array}$ & 0,868 \\
\hline 2 & $\begin{array}{l}\text { Dokter menanyakan } \\
\text { keluhan pasien (X16) }\end{array}$ & 0,575 \\
\hline
\end{tabular}

e. Faktor kelima memberikan bobot kontribusi sebesar 6,078\%. Berdasarkan hasil rotasi urutan variabel yang dominan dalam menjelaskan faktor kelima $\left(\mathrm{F}_{5}\right)$ diperlihatkan pada tabel 5 :

Tabel 5. Rotasi Komponen Matrix lima

\begin{tabular}{|c|c|c|}
\hline Urutan & Variabel & $\begin{array}{l}\text { Nilai } \\
\text { Loading }\end{array}$ \\
\hline 1 & $\begin{array}{l}\text { Perawat } \\
\text { ramah dersikap } \\
(\mathrm{X} 19)\end{array}$ & 0,713 \\
\hline 2 & $\begin{array}{l}\text { Kebersihan } \\
\text { makan dan minum } \\
\text { (X8) }\end{array}$ & 0,600 \\
\hline
\end{tabular}

f. Faktor keenam memberikan bobot kontribusi sebesar 5,393\%. Berdasarkan hasil rotasi urutan variabel yang dominan dalam menjelaskan faktor keenam $\left(\mathrm{F}_{6}\right)$ diperlihatkan pada tabel 6:

Tabel 6. Rotasi Komponen Matrix enam

\begin{tabular}{|c|c|c|}
\hline Urutan & Variabel & $\begin{array}{l}\text { Nilai } \\
\text { Loading }\end{array}$ \\
\hline 1 & $\begin{array}{lr}\text { Kursi roda tersedia } \\
\text { untuk membantu } \\
\text { membantu } \\
\text { penerimaan } \\
\text { kebutuhan dan } \\
\left(\mathrm{X}_{5}\right) & \text { pasien } \\
& \end{array}$ & 0,709 \\
\hline 2 & $\begin{array}{l}\text { Tersedia dokter } \\
\text { spesialis (X25) }\end{array}$ & 0,445 \\
\hline
\end{tabular}

g. Faktor ketujuh memberikan bobot kontribusi sebesar 5,003\%. Berdasarkan hasil rotasi urutan variable yang dominan dalam menjelaskan faktor ketujuh $\left(\mathrm{F}_{7}\right)$ diperlihatkan pada tabel 7 :

Tabel 7. Rotasi Komponen Matrix tujuh

\begin{tabular}{|c|l|l|}
\hline Urutan & \multicolumn{1}{|c|}{ Variabel } & $\begin{array}{l}\text { Nilai } \\
\text { Loading }\end{array}$ \\
\hline 1 & $\begin{array}{l}\text { Dokter memberikan } \\
\text { kesempatan bertanya } \\
\text { pada pasien(X17) }\end{array}$ & 0,843 \\
\hline 2 & $\begin{array}{l}\text { Perawat terdidik dan } \\
\text { mampu r melayani } \\
\text { pasien } \\
\text { kebutuhan sesuai } \\
\text { X27) }\end{array}$ & $\mathbf{0 , 4 0 1}$ \\
\hline
\end{tabular}

h. Faktor kedelapan memberikan bobot kontribusi sebesar 4,963\%. Berdasarkan hasil rotasi urutan variabel yang dominan dalam menjelaskan faktor kedelapan $\left(\mathrm{F}_{8}\right)$ diperlihatkan pada tabel 8:

Tabel 8. Rotasi Komponen Matrix delapan

\begin{tabular}{|c|l|l|}
\hline $\begin{array}{l}\text { Ur } \\
\text { uta } \\
\mathrm{n}\end{array}$ & \multicolumn{1}{|c|}{ Variabel } & $\begin{array}{l}\text { Nilai } \\
\text { Loadin } \\
\mathrm{g}\end{array}$ \\
\hline $\mathbf{1}$ & $\begin{array}{l}\text { Kesiapan perawat dalam melayani } \\
\text { pasien (X13) }\end{array}$ & 0,595 \\
\hline $\mathbf{2}$ & $\begin{array}{l}\text { Perilaku dokter membantu } \\
\text { menimbulkan rasa aman pada } \\
\text { pasien selama masa perawatan } \\
\text { (X26) }\end{array}$ & \\
\hline
\end{tabular}

i. Faktor kesembilan memberikan bobot kontribusi sebesar 4,616\%. Berdasarkan hasil urutan variabel yang dominan dalam menjelaskan faktor kedelapan $\left(\mathrm{F}_{9}\right)$ diperlihatkan pada tabel 9:

Tabel 9. Rotasi Komponen Matrix sembilan

\begin{tabular}{|c|l|l|}
\hline Urutan & \multicolumn{1}{|c|}{ Variabel } & $\begin{array}{l}\text { Nilai } \\
\text { Loading }\end{array}$ \\
\hline 1 & $\begin{array}{l}\text { Kesiapan dokter } \\
\text { melayani pasien (X11) }\end{array}$ & 0,761 \\
\hline
\end{tabular}




\section{KESIMPULAN DAN SARAN \\ Kesimpulan}

Analisis faktor dapat digunakan untuk mengetahui tingkat pelayanan dan kepuasan pasien Rumah Sakit TK-II R.W Mongisidi dengan faktor-faktor yang mempengaruhi proses analisis terdapat 9 faktor yang berkorelasi dimana faktor satu memberikan kontribusi sebesar 12,577\%, faktor dua sebesar 10,821\%, faktor tiga $7,987 \%$, faktor empat $7,046 \%$, faktor lima $6,078 \%$, faktor enam 5,393\%, faktor tujuh 5,003\%, faktor delapan 4,963\% dan faktor Sembilan sebesar $4,616 \%$ maka hasil yang diperoleh cukup puas dengan nilai $64,484 \%$

\section{Saran}

1. Dalam penelitian selanjutnya dapat menggunakan metode yang berbeda untuk mendapatkan tingkat kepuasan yang lebih baik dan tinggi.

2. dalam analisis data dapat diolah secara manual untuk mendapatkan hasil yang berbeda yang dapat digunakan sebagai perbandingan antara uji manual dan uji menggunakan aplikasi.

\section{DAFTAR PUSTAKA}

[1] Ariyanti, M. 2009. Pengaruh Kualitas Pelayanan Terhadap Kepuasan Mahasiswa Universitas Widyatama [Skripsi]. Universitas Widyatama. Bandung.

[2] Dwipurwani, . 2009. Penerapan Analisis Faktor dalam Membentuk Faktor Laten yang mempengaruhi Prestasi Mahasiswa di Jurusan Matematika FMIPA Universitas Sriwijaya. Jurnal Penelitian Sains (JPS). 12 (3 (A)) :12301-12305.

[3] Ghozali, I. 2006. Aplikasi Multivariate dengan Program SPSS. Badan Penerbit UNDIP. Semarang.

[4] Laksono I.N, 2008. Analisis Kepuasan dan Hubungannya dengan Loyalitas Pasien Rawat Inap di Rumah Sakit Dedi Jaya Kabupaten Brebes Program Pasca Sarjana Universitas Udayana.

[5] Lombone, I., M. S. Paendong., Y. A. R. Langi (2012). Tingkat kepuasan mahasiswa terhadap kualitas pelayanan Universitas Sam Ratulangi menggunakan metode Analisis Faktor Jurusan Matematika Fakultas Mipa Universitas Sam Ratulangi. Jurnal MIPA Unsrat Online 1 (1) : 52-56.

[6] Mamahit, S., M. S. Paendong., Y. A. R. Langi. 2013. Tingkat Kepuasan Dosen Dan Tenaga Kependidikan Terhadap Pelayanan Universitas Sam Ratulangi Menggunakan Analisis Faktor. Jurusan Matematika Universitas Sam Ratulangi Manado. Jurnal Ilmiah Sains 13(1) : 1-10.

[7] Supranto, J. 2004. Analisis Multivariat: Arti dan Interpretasi, Jakarta, PT. Rineka Cipta

[8] Widarjano, A. 2010. Analisis Stastistika Multivariat Terapan. UPP STIM YKPN. Yogyakarta
Rocky R Lintong (rockylintong@gmail.com)

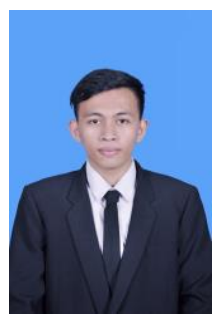

Lahir di Pinamorongan, Pada tanggal 16 maret 1997. Menempuh pendidikan tinggi di Jurusan Matematika FMIPA, Universitas Sam Ratulangi Manado. Tahun 2019 adalah tahun terakhir ia menempuh studi. Makalah ini merupakan hasil penelitian skripsinya yang dipublikasikan.

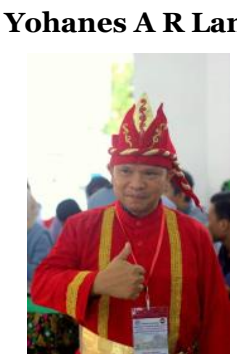

gi (yarangi@gmail.com)

Lahir di Jakarta pada tanggal 13 Juni 1970. Pada tahun 1994 mendapatkan gelar Sarjana Sains (S.Si) yang diperoleh dari Universitas Kristen Indonesia - Tomohon. Gelar Master Sains (M.Si) diperoleh dari Institut Pertanian Bogor pada tahun 2007. Ia bekerja di UNSRAT di Program Studi akademik tetap UNSRAT. Matematika sebagai pengajar

Charles E. Mongi (charlesmongi@unsrat.ac.id)

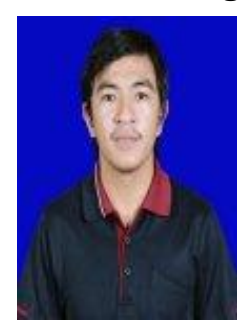

Lahir di Tomohon, Minahasa Pada tanggal 4 januari 1984. Pada tahun 2006 memperoleh gelar sarjana pada program studi Matematika, Universitas Sam Ratulangi Manado, gelar Magister Sains diperoleh dari Institut Pertanian Bogor pada tahun 2014. Dan menjadi dosen dijurusan Matematika FMIPA Universitas Sam Ratulangi Manado Pada tahun 2008 sampai sekarang. 